\title{
VOICE AMPLIFICATION FOR PRIMARY SCHOOL TEACHERS WITH VOICE DISORDERS: A RANDOMIZED CLINICAL TRIAL
}

\section{ROBERTO BOVO, PATRIZIA TREVISI, ENZO EMANUELLI, and ALESSANDRO MARTINI}

Padua University, Padua, Italy

Operative Unit of Otolaryngology and Otosurgery

\begin{abstract}
Objectives: Several studies have demonstrated a high prevalence of voice disorders in teachers, together with the personal, professional and economical consequences of the problem. Good primary prevention should be based on 3 aspects: 1) amelioration of classroom acoustics, 2) voice care programs for future professional voice users, including teachers and 3) classroom or portable amplification systems. The aim of the study was to assess the benefit obtained from the use of portable amplification systems by female primary school teachers in their occupational setting. Materials and Methods: Forty female primary school teachers attended a course about professional voice care, which comprised two theoretical lectures, each 60 min long. Thereafter, they were randomized into 2 groups: the teachers of the first group were asked to use a portable vocal amplifier for 3 months, till the end of school-year. The other 20 teachers were part of the control group, matched for age and years of employment. All subjects had a grade 1 of dysphonia with no significant organic lesion of the vocal folds. Results: Most teachers of the experimental group used the amplifier consistently for the whole duration of the experiment and found it very useful in reducing the symptoms of vocal fatigue. In fact, after 3 months, Voice Handicap Index (VHI) scores in "course + amplifier" group demonstrated a significant amelioration $(\mathrm{p}=0.003)$. The perceptual grade of dysphonia also improved significantly $(p=0.0005)$. The same parameters changed favourably also in the "course only" group, but the results were not statistically significant ( $\mathrm{p}=0.4$ for VHI and $\mathrm{p}=0.03$ for perceptual grade). Conclusions: In teachers, and particularly in those with a constitutional weak voice and/or those who are prone to vocal fold pathology, vocal amplifiers may be an effective and low-cost intervention to decrease potentially damaging vocal loads and may represent a necessary form of prevention.
\end{abstract}

Key words:

Voice disorders, Teachers, Prevention, Vocal amplifier, Education, Vocal rehabilitation

\section{INTRODUCTION}

Several studies have demonstrated a high prevalence of voice disorders in teachers, as well as the personal, professional and economical relevance of the problem [1-4]. Moreover, some reports seem to indicate that poor voice quality in teachers reduces the intelligibility of their speech and the cognitive functioning and successful learning of the students [5,6]. Teachers are at risk of developing vocal disorders because, due to speaking in conditions of high background noise level, they naturally increase vocal loudness, which causes increased $\mathrm{F}_{0}$ and, mostly in untrained speakers, strained or hyperfunctional vocal behaviour. In fact, most teachers tend to keep their voices at an intensity of about $10-15 \mathrm{~dB}$ above the environmental noise, that is well above the physiological intensity of a conversational voice.

Received: September 9, 2012. Accepted: April 25, 2013.

Corresponding author: R. Bovo, Operative Unit of Otolaryngology and Otosurgery, Padua University, Via Giustiniani, 2, 35121 Padua, Italy (e-mail: roberto.bovo@sanita.padova.it). 
A good primary prevention should be based on three aspects: 1) amelioration of classroom acoustics, 2) voice care programs for the future professional voice users, including teachers, and 3) classroom or portable amplification systems. Unfortunately, these interventions are only possible in rare situations due to a lack of financial resources, sometimes due to low ranking of the problem by school administrations and authorities.

\section{Amelioration of classroom acoustics}

Noise and reverberation have a detrimental synergic effect either on speech intelligibility, or on teacher voice demand. In large occupied classrooms, reverberation time frequently exceeds $1 \mathrm{~s}$ (recommended reverberation ranges from 0.4 to $0.5 \mathrm{~s}$ ) and the noise is higher than $55-60 \mathrm{~dB}$, especially in day care centres and primary schools [7]. New schools are designed following specific requirements [8], but in old school buildings, acoustic conditions are frequently very poor as reported by different surveys from all developed countries. Nevertheless, an amelioration of classroom acoustics is now possible with low cost materials. In particular, wall absorber panels and an acoustic ceiling can reduce reverberation time and sound level. The basic sound pressure levels (SPL) in classrooms with reverberation times of less than $0.5 \mathrm{~s}$ are $8 \mathrm{~dB}$ lower than in classrooms with reverberation times of between 0.6 and $0.8 \mathrm{~s}$. Furthermore, an efficient voice amplification system can only be successfully implemented in classrooms with suitable reverberation times.

\section{Vocal education programs for teachers}

Consecutive questionnaires submitted to different teacher populations generally indicate that subjects had poor knowledge of voice care problems, especially regarding symptoms of vocal fatigue, vocal hygiene and the correct use of voice [9,4]. For these reasons, several authors have underlined the fact that vocal education programs for teachers, which include correct voice use training and vocal hygiene, may prevent the development of these pathologies and stimulate teachers to seek medical assistance before the onset of the vicious circle of a vocal disorder. Literature has demonstrated the effectiveness of voice group therapy, although some aspects are still debatable [10].

\section{Amplification}

One specific treatment approach to reduce vibration dose is to provide the teacher with an electronic voice amplification system for usage in the classroom. It is expected that, by reducing loudness levels and thus vibration dose, the degree of tissue injury due to collision and shearing forces can be reduced, eventually leading to improvement in voice quality and reduced vocal recovery times.

Furthermore, a subpopulation of teachers are particularly prone to developing a vocal fold pathology and/or have a constitutional weak voice [11], i.e. they are not able to reach a voice intensity level of $90 \mathrm{~dB}$ SPL during a maximum intensity vocal emission. These subjects are at risk for voice disorders even when they strictly adhere to vocal hygiene recommendations and after they have acquired a correct vocal technique. For these subjects, the use of a vocal amplifier is absolutely necessary. Currently, there are numerous voice amplification systems available to teachers that vary considerably in design, quality, and cost. Sound-field frequency modulation (FM) systems (with one or more strategically located speakers), and portable personal voice amplifiers are two popular approaches to provide voice amplification in the classroom. Costs for such systems vary considerably, and each system has inherent advantages and disadvantages. Sound-field FM systems detect the speaker's voice using an FM wireless microphone typically situated within 3 to 4 inches of the speaker's mouth. The speaker's voice is converted into an electrical signal and transmitted by an FM carrier frequency to an FM receiver. The signal is then amplified, transformed into the acoustic waveform, and transmitted via one or more loudspeakers to the audience. With 
stationary FM systems, voice amplification occurs only in the classroom where the loudspeakers are located. However, teachers regularly use their voice in situations other than during classroom instruction, for instance in the hallway, lunchroom, playground, gymnasium, and during other extracurricular activities. Many of these circumstances demand even greater increases in vocal loudness levels. Portable, marsupium-like amplifiers are economical, can be used in different situations and are less affected by poor environmental acoustic conditions compared to stationary FM systems, which demand low environmental reverberation. On the other hand, sound quality and amplification gain are lower in portable amplifiers when compared with stationary FM systems.

Despite an increase in the selection and popularity of voice amplification in the classroom, only sporadic studies have objectively evaluated the effects of these instruments on reducing the speaker's vocal demand. In the first years of this decade, a few studies demonstrated that portable systems permit up to $6.0 \mathrm{~dB}$ SPL reduction of the voice intensity during a simulated classroom lecture [12-14]. Furthermore, among a group of 33 teachers, 97\% reported easier voice production and $82 \%$ found improved vocal endurance [15]. More recently, the vocal portable dosimeters (KayPENTAX Ambulatory Phonation Monitor) permit a more reliable monitoring of vocal dose in an occupational setting. In fact, these instruments permit the determination of average vocal intensity (dB SPL) and vocal load, as calculated by cycle dose and distance dose. In a study by Gaskill et al. [16], two teachers wore a portable amplifier for two weeks: each teacher showed a reduction in vocal intensity during the week of amplification, with a larger effect for the teacher with vocal difficulties. After providing the same instrument to seven elementary music teachers, Morrow and Connor [17] demonstrated that, with the amplifier, mean vocal intensity was reduced by 7.0 dB SPL ( $<<0.001)$. Cycle dose and distance dose also decreased significantly $(p=0.001)$, while mean phonation time changed in the desired direction, although not significantly ( $p=0.023)$. Roy [18] compared treatment outcomes in three groups of teachers: a voice amplification group (VA), a vocal hygiene group (VH) and a nontreatment control group. The results demonstrated that both treatment groups improved significantly compared to the control group and there were no significant differences between VA and VH. However, a post-treatment questionnaire revealed that the VA group reported greater ease and more clarity in voice production and a greater compliance to the treatment. In another study, the same author [19] confronted portable amplification vs. resonant voice therapy, breathing muscles training and vocal hygiene: amplification proved to be the most effective.

The aim of this study was to evaluate the benefit of an economical portable amplifier on the voice fatigue and voice quality in a group of primary school teachers.

\section{MATERIALS AND METHODS}

Every two years since 1999, we have conducted a course in professional voice care for school teachers, which comprise two theoretical lectures, each $60 \mathrm{~min}$ long, and two sessions of group voice therapy, each of $120 \mathrm{~min}$. Details have been previously described elsewhere [9]. The participants, mostly kindergarten and primary school female teachers, are representative of a homogeneous population with a high vocal demand, are very interested and well motivated in the prevention of vocal disturbances, and most of them have reported vocal fatigue after vocal effort, with a low incidence $(<2 \%)$ of organic lesions of surgical interest.

During the most recent course, teachers attended only the two theoretical lectures, without direct intervention. In fact, the subjects for the present study were enrolled from the course participants and it was decided to compare the experimental group with a control group whose subjects received minimal intervention which, however, was sufficient 
to remain in agreement with ethical considerations. Among the participants of this last course, 42 teachers met the following inclusion criteria: (i) female gender, (ii) full time employment as primary school teachers ( $22 \mathrm{~h} /$ week), and (iii) motivation to collaborate. The exclusion criteria were previously treated dysphonia, smoking or alcohol habits, neurological or endocrine disease, psychiatric disturbances, acid reflux, multiple medical complaints, vocal fold lesion as polyps, paralysis, papillomas, or severe dysphonia requiring urgent intervention, allergies, and other recurrent upper respiratory tract diseases. On entry into the study, all 42 teachers gave their consent for inclusion. They underwent a phoniatric examination which comprised laryngoscopy and a blinded perceptive voice evaluation. To quantify the grade of dysphonia, a visual analogue scale (VAS), $100 \mathrm{~mm}$ in length, with grades from 0 (best vocal quality) to 100 (poorest vocal quality) was used. Two MD phoniatricians with more than 20 years of experience, the first two authors of this paper, marked on the VAS the point that they felt represented their perception of the global grade of dysphonia. The scores corresponded to the distance, in $\mathrm{mm}$, from the left point of the scale. Thus, they had a potential range from 0 to 100 with the higher score correlating with maximum grade of dysphonia.

Furthermore, the examined female teachers were requested to complete the Voice Handicap Index (VHI) questionnaire [20], a 30-item self assessment scale which allows the the subject to evaluate her perception of the impact of her vocal difficulties. The VHI adopts a five-point scale, which assigns a number to how frequently the subject experiences each of the statements, with $0=$ never and $4=$ frequently. The scores have a potential range from 0 to 120 , with the higher score correlating with greater impact. The VHI was applied to subjects of both groups at the same time, corresponding to the first day of the course and then 3 months later.

Two teachers were excluded because they did not respect the inclusion criteria and the 40 remaining underwent a computer generated randomization into 2 groups of 20 elements.
The teachers of the first group $(\mathrm{P})$ were asked to use a portable vocal amplifier for 3 months, until the end of the school year. As these teachers had also received benefits from the vocal hygiene norms which were illustrated during the course, this group will be identified as "course + amplifier". The other 20 teachers were the control group $(\mathrm{C})$, which did not receive any direct treatment; however, they benefited from vocal hygiene norms, and so it will be identified as the "course only" group. The teachers from "course only" and from "course + amplifier" groups were matched for age and years of employment, as reported in Table 1. All teachers were re-examined at the end of school year by the same voice evaluation performed 3 months before, as illustrated in Figure 1. The amplifier (Proel ${ }^{\circledR}$ WAP1) is a belt-bag portable speaker equipped with a headset condenser microphone,

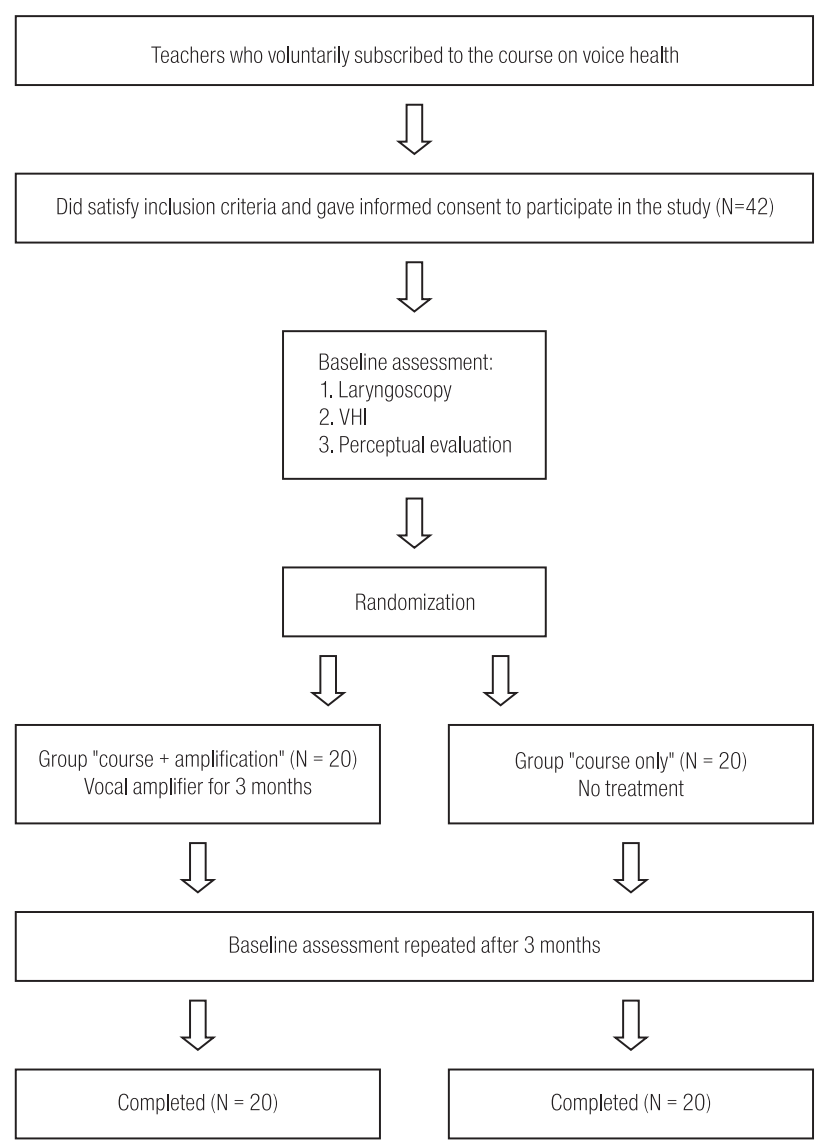

Fig. 1. Study design 
Table 1. Bio-anagraphical data of subjects from tested groups

\begin{tabular}{|c|c|c|c|c|c|}
\hline \multicolumn{3}{|c|}{$\begin{array}{l}\text { "Course and amplifier" group } \\
\qquad(\mathrm{N}=20)\end{array}$} & \multicolumn{3}{|c|}{$\begin{array}{l}\text { "Course only" group } \\
(\mathrm{N}=20)\end{array}$} \\
\hline patient & $\begin{array}{l}\text { age } \\
\text { (years) }\end{array}$ & $\begin{array}{l}\text { period of employment } \\
\text { (years) }\end{array}$ & control & $\begin{array}{l}\text { age } \\
\text { (years) }\end{array}$ & $\begin{array}{l}\text { period of employment } \\
\text { (years) }\end{array}$ \\
\hline $\mathrm{P} 1$ & 55 & 10 & $\mathrm{C} 1$ & 42 & 14 \\
\hline $\mathrm{P} 2$ & 38 & 18 & $\mathrm{C} 2$ & 43 & 18 \\
\hline P3 & 56 & 35 & $\mathrm{C} 3$ & 52 & 30 \\
\hline P4 & 50 & 25 & $\mathrm{C} 4$ & 47 & 23 \\
\hline P5 & 30 & 9 & $\mathrm{C} 5$ & 34 & 12 \\
\hline P6 & 39 & 8 & C6 & 42 & 12 \\
\hline P7 & 55 & 32 & $\mathrm{C} 7$ & 55 & 30 \\
\hline P8 & 50 & 23 & $\mathrm{C} 8$ & 44 & 24 \\
\hline P9 & 36 & 8 & $\mathrm{C} 9$ & 34 & 7 \\
\hline P10 & 38 & 12 & $\mathrm{C} 10$ & 40 & 8 \\
\hline P11 & 53 & 28 & $\mathrm{C} 11$ & 50 & 26 \\
\hline P12 & 37 & 6 & $\mathrm{C} 12$ & 40 & 10 \\
\hline $\mathrm{P} 13$ & 55 & 28 & $\mathrm{C} 13$ & 49 & 28 \\
\hline P14 & 34 & 8 & $\mathrm{C} 14$ & 36 & 20 \\
\hline P15 & 52 & 7 & $\mathrm{C} 15$ & 39 & 11 \\
\hline P16 & 58 & 38 & $\mathrm{C} 16$ & 54 & 18 \\
\hline P17 & 50 & 27 & $\mathrm{C} 17$ & 50 & 25 \\
\hline P18 & 40 & 9 & $\mathrm{C} 18$ & 35 & 8 \\
\hline P19 & 38 & 17 & $\mathrm{C} 19$ & 42 & 16 \\
\hline P20 & 39 & 13 & $\mathrm{C} 20$ & 41 & 9 \\
\hline $\mathrm{M} \pm \mathrm{SD}$ & $45.15 \pm 8.92$ & $18.05 \pm 10.50$ & & $43.45 \pm 6.53$ & $17.45 \pm 7.84$ \\
\hline
\end{tabular}

M - mean; SD - standard deviation.

which operates with normal or rechargeable batteries. Its weight is $0.45 \mathrm{~kg}$, dimensions are $18 \times 8 \times 6 \mathrm{~cm}$.

This clinical investigation was conducted in accordance with the ethical regulations of the Declaration of Helsinki, as revised in 1983, and in adherence to standards of the regional committee responsible for human experimentation.

\section{Statistical analyses}

Although no formal calculation of sample size was performed, 40 subjects were considered to be an appropriate number for analysis of the results. Statistical analyses were carried out with the Student's t test, and $\mathrm{p}<0.01$ was considered statistically significant. 


\section{RESULTS}

All teachers of both groups completed the study and none of them missed any days of work, reduced their working hours or practised vocal exercises in the 3-month period. Table 2 shows the modes and time of usage of the amplifier, and grade of satisfaction by teachers. Ten teachers $(50 \%)$ used the amplifier continuously during the entire study period. Eight (40\%) teachers used it for a few hours a day or for 2-3 days a week. Two teachers (10\%) did not use the amplifier: one was complaining of excessive weight and was not able to solve the problem of the Larsen effect, while the second was a gym teacher. Two (10\%) amplifiers were damaged. All teachers, both those who used the amplifier full-time and those who did not use it continuously, found it useful (6/20), or very useful (8/20) in reducing the symptoms of vocal fatigue.

Table 2. Modes, time of usage of the amplifier, grade of satisfaction by "course + amplifier" group

\begin{tabular}{|c|c|}
\hline Patient & Time of usage, grade of satisfaction \\
\hline $\mathrm{P} 1$ & $\begin{array}{l}\text { Used only 2-3 days. } \\
\text { Fastidious, too heavy, Larsen effect. }\end{array}$ \\
\hline $\mathrm{P} 2$ & $\begin{array}{l}\text { Used only few weeks, then batteries broke down. } \\
\text { Great benefit during the short period of use. }\end{array}$ \\
\hline P3 & $\begin{array}{l}\text { Used full-time, for the whole lesson time. } \\
\text { Great benefits, laryngeal paresthesias disappeared. }\end{array}$ \\
\hline P4 & Used full-time, for the whole lesson time, both in classroom and in gymnasium. Very satisfied. \\
\hline P5 & $\begin{array}{l}\text { She did not use it at school, because she works mainly in gymnasium, and it "makes too much noise". She uses it in the } \\
\text { evening, when she teaches dancing. }\end{array}$ \\
\hline P6 & $\begin{array}{l}\text { Used full-time, for the whole lesson time, both in classroom and in common areas. Very satisfied, laryngeal irritation } \\
\text { disappeared. }\end{array}$ \\
\hline P7 & $\begin{array}{l}\text { Used full-time, for the whole lesson time, but not in open space, except during the school-drama. Laryngeal irritation and } \\
\text { dryness subjectively reduced. }\end{array}$ \\
\hline P8 & $\begin{array}{l}\text { After } 20 \text { days, the amplifier broke down. In the last period she used the instrument. She complains of excessive weight and } \\
\text { dimensions. She however felt benefits. She would like to have a lighter one. }\end{array}$ \\
\hline P9 & Used full time, with good benefits. Useful in the canteen and in the gymnasium, too. \\
\hline $\mathrm{P} 10$ & Used full time, with good benefits. Vocal stress was reduced, with the amplifier. She noticed a reduction in general stress. \\
\hline P11 & $\begin{array}{l}\text { Used for the first } 3 \text { weeks with amelioration of voice fatigue; then for a short period of } 3-4 \text { days, every time she noticed } \\
\text { improved symptoms. She considered the amplifier very useful. }\end{array}$ \\
\hline $\mathrm{P} 12$ & Used full time in the canteen and in the gymnasium, too. Not so useful during the classroom lessons. \\
\hline $\mathrm{P} 13$ & Used full-time, for the whole lesson time, both in classroom and in common areas. \\
\hline P14 & Used for 2-3 days a week, particularly on Tuesdays and Fridays. She considered the amplifier useful, but a bit too heavy. \\
\hline P15 & Used only for 1-2 $\mathrm{h}$ a day, but with benefit. Laryngeal irritation subjectively reduced. \\
\hline P16 & $\begin{array}{l}\text { Used full-time, for the whole lesson time, both in classroom and in common areas. Significant benefit in laryngeal dryness } \\
\text { and paresthesias. }\end{array}$ \\
\hline $\mathrm{P} 17$ & $\begin{array}{l}\text { Used regularly for the first } 2 \text { months, then from time to time, when experiencing worsening of laryngeal dryness and vocal } \\
\text { fatigue. Reported a significant benefit. }\end{array}$ \\
\hline P18 & Used full time, with great benefits. No complaints. \\
\hline P19 & Generally used for $2-3 \mathrm{~h}$ a day, with benefit. She reported a significant amelioration of cervical pain. \\
\hline $\mathrm{P} 20$ & $\begin{array}{l}\text { She complains of excessive weight and dimensions. She however felt benefits by a daily use of } 2-3 \mathrm{~h} \text {. She would like to buy } \\
\text { a lighter one. }\end{array}$ \\
\hline
\end{tabular}


Table 3. VHI Scores for "course + amplifier" group and "course only" group

\begin{tabular}{|c|c|c|c|c|c|}
\hline \multicolumn{3}{|c|}{ "Course + amplifier" group } & \multicolumn{3}{|c|}{ "Course only" group } \\
\hline patient & VHI baseline & VHI after 3 months & control & VHI baseline & VHI after 3 months \\
\hline $\mathrm{P} 1$ & 15 & 14 & $\mathrm{C} 1$ & 3 & 1 \\
\hline $\mathrm{P} 2$ & 11 & 7 & $\mathrm{C} 2$ & 12 & 9 \\
\hline P3 & 7 & 8 & $\mathrm{C} 3$ & 2 & 3 \\
\hline P4 & 13 & 12 & $\mathrm{C} 4$ & 14 & 12 \\
\hline P5 & 15 & 9 & C5 & 2 & 3 \\
\hline P6 & 23 & 6 & C6 & 11 & 10 \\
\hline P7 & 8 & 10 & $\mathrm{C} 7$ & 7 & 9 \\
\hline P8 & 10 & 8 & $\mathrm{C} 8$ & 15 & 16 \\
\hline P9 & 8 & 6 & $\mathrm{C} 9$ & 5 & 1 \\
\hline P10 & 6 & 6 & $\mathrm{C} 10$ & 10 & 10 \\
\hline P11 & 16 & 10 & $\mathrm{C} 11$ & 6 & 4 \\
\hline $\mathrm{P} 12$ & 21 & 9 & $\mathrm{C} 12$ & 12 & 13 \\
\hline $\mathrm{P} 13$ & 13 & 15 & $\mathrm{C} 13$ & 7 & 8 \\
\hline P14 & 4 & 2 & $\mathrm{C} 14$ & 3 & 5 \\
\hline P15 & 12 & 11 & $\mathrm{C} 15$ & 2 & 0 \\
\hline P16 & 13 & 7 & $\mathrm{C} 16$ & 18 & 15 \\
\hline P17 & 3 & 5 & $\mathrm{C} 17$ & 9 & 7 \\
\hline P18 & 9 & 7 & $\mathrm{C} 18$ & 3 & 11 \\
\hline P19 & 10 & 6 & $\mathrm{C} 19$ & 14 & 15 \\
\hline $\mathrm{P} 20$ & 16 & 10 & $\mathrm{C} 20$ & 24 & 24 \\
\hline $\mathrm{M} \pm \mathrm{SD}$ & $11.65 \pm 5.17$ & $8.4 \pm 3.12$ & & $8.95 \pm 6.08$ & $8.8 \pm 6.08$ \\
\hline
\end{tabular}

Abbreviations as in Table 1.

VHI score and perceptual grade of dysphonia, baseline and after 3 months, for the course + amplifier group and the course only group, are reported in Tables 3 and 4.

The VHI demonstrated a statistically significant improvement for the experimental group at time $=3$ months ( $p=0.003$ ), whereas for the control group the difference between time zero and time 3 months was not statistically significant $(\mathrm{p}=0.4)$.

The perceptual grade of dysphonia demonstrated a statistically significant improvement for the experimental group at time $=3$ months $(p=0.0005)$, whereas for the control group, the difference between time zero and time 3 months was not statistically significant $(p=0.03)$.

\section{DISCUSSION}

The purpose of our study was to investigate the effectiveness of a preventive cost-efficient treatment, i.e. the use of a portable amplifier, on a homogeneous group of teachers. In addition, the experimental and control groups received two lectures on voice care, which were necessary (i) to enrol a group of motivated, homogeneous teachers with a low grade of dysphonia and, (ii) to provide minimal treatment 
Table 4. Grade of Perceptual Dysphonia for "course + amplifier" group and "course only" group

\begin{tabular}{|c|c|c|c|c|c|}
\hline \multicolumn{3}{|c|}{ "Course + amplifier" group } & \multicolumn{3}{|c|}{ "Course only" group } \\
\hline patient & $\begin{array}{l}\text { perceptual grade } \\
\text { baseline* } \\
(\mathrm{mm})\end{array}$ & $\begin{array}{l}\text { perceptual grade } \\
\text { after } 3 \text { months* } \\
(\mathrm{mm})\end{array}$ & control & $\begin{array}{l}\text { perceptual grade } \\
\text { baseline* } \\
(\mathrm{mm})\end{array}$ & $\begin{array}{l}\text { perceptual grade } \\
\text { after } 3 \text { months* } \\
(\mathrm{mm})\end{array}$ \\
\hline$\overline{\mathrm{P} 1}$ & 13 & 11 & $\mathrm{C} 1$ & 3 & 2 \\
\hline $\mathrm{P} 2$ & 40 & 13 & $\mathrm{C} 2$ & 25 & 17 \\
\hline P3 & 12 & 3 & $\mathrm{C} 3$ & 9 & 7 \\
\hline $\mathrm{P} 4$ & 22 & 23 & $\mathrm{C} 4$ & 25 & 11 \\
\hline P5 & 35 & 19 & $\mathrm{C} 5$ & 16 & 4 \\
\hline P6 & 42 & 9 & C6 & 4 & 15 \\
\hline P7 & 12 & 12 & $\mathrm{C} 7$ & 9 & 9 \\
\hline P8 & 62 & 20 & $\mathrm{C} 8$ & 10 & 8 \\
\hline P9 & 18 & 3 & $\mathrm{C} 9$ & 24 & 7 \\
\hline $\mathrm{P} 10$ & 8 & 15 & $\mathrm{C} 10$ & 12 & 10 \\
\hline P11 & 18 & 12 & $\mathrm{C} 11$ & 9 & 7 \\
\hline $\mathrm{P} 12$ & 14 & 5 & $\mathrm{C} 12$ & 11 & 8 \\
\hline $\mathrm{P} 13$ & 32 & 21 & $\mathrm{C} 13$ & 14 & 16 \\
\hline P14 & 10 & 10 & $\mathrm{C} 14$ & 7 & 8 \\
\hline P15 & 13 & 1 & $\mathrm{C} 15$ & 18 & 2 \\
\hline P16 & 43 & 16 & $\mathrm{C} 16$ & 28 & 8 \\
\hline P17 & 23 & 24 & $\mathrm{C} 17$ & 27 & 12 \\
\hline P18 & 46 & 13 & $\mathrm{C} 18$ & 8 & 20 \\
\hline P19 & 61 & 19 & C19 & 8 & 7 \\
\hline P20 & 14 & 9 & $\mathrm{C} 20$ & 8 & 5 \\
\hline Mean \pm SD & $26.9 \pm 17.04$ & $12.9 \pm 6.78$ & & $13.75 \pm 7.97$ & $9.15 \pm 4.83$ \\
\hline
\end{tabular}

Abbreviations as in Table 1.

* On a video-analog scale of $100 \mathrm{~mm}$ length.

to all the teachers, who were requesting some form of medical help for their voice disturbances. Nevertheless, it was beyond the scope of our study to compare the possible benefit of voice amplification versus different preventive approaches; these comparisons are difficult because of uneven levels of compliance, as discussed by Roy et al. [18].

As observed in a previous study [9], the teachers who voluntarily subscribed to our courses demonstrated collaboration and motivation in improving voice quality and in reducing voice fatigue. In fact, all teachers completed the study with a drop-out incidence that was far less than in other study designs [18,21,22].
Among the experimental group, 50\% used the amplifier continuously and $40 \%$ used it for a limited time but with great success. Only two teachers reported unfavourable experience with the amplifier: they complained of excessive weight and Larsen effect when the microphone was too close to the amplifier (e.g. when they had to approach the benches to help the schoolchildren).The other teachers solved this problem by switching the amplifier off when they approached children, or, if they were sitting at the bench, by putting it on the surface, thus keeping an adequate distance between the microphone and the loudspeaker. Finally, others attached the 
amplifier to the back of their belt to keep it away from the microphone.

The gym teacher reported the most serious problems attributable to poor environmental acoustic conditions (i.e. very high reverberation in the gymnasium) and impediment of the freedom of body movements by the excessive size of the portable instrument. On the other hand, other subjects used the amplifier in an open space and in common areas with good results.

In order to solve portability problems, maybe small-sized amplifiers could be purchased and smaller batteries would reduce the weight and the total size of the equipment. It is to be noted that, among the several portable amplifier commercially available, a few are smaller and one weighs around $0.2 \mathrm{~kg}$, that is to say, half the weight of the one we provided to our teachers. The weight is probably a relevant factor, as prolonged use of the amplifier could possibly cause damage related to incorrect postures.

An unpredictable event was the damage of 2 amplifiers, one of them probably due to one teacher's negligence, the other one due to an electronic failure. Among these two teachers, one reported benefit during the short period of use, the other considered the instrument too heavy, although helpful in reducing vocal fatigue.

The VHI scores in the "course + amplifier group" significantly improved ( $p<0.01)$, while for the "course only" group, VHI did not change in a significant way. It should be noted that VHI scores in our teachers were very low, thus reducing the statistical power of the test, particularly in the limited number of subjects examined. The perceptual grade of dysphonia in the "course + amplifier" group also improved significantly $(p<0.001)$. The same parameter changed in the desired direction also in "course only" group, but results were not statistically significant ( $\mathrm{p}=0.03$ ). Thus, auto-evaluation and objective tests seem to demonstrate a higher benefit in the group "course + amplifier" with respect to the "course only group".
In our study design, it was decided to exclude objective laryngeal evaluation as a test to evaluate the benefit of the treatment. In fact, other authors did not observe any major differences between group/treatments regarding laryngeal examination, particularly in patients with low grade dysphonia $[21,23]$. In any case, laryngeal examination was used in this study mostly to rule out vocal fold lesions of surgical interest.

The improvement in voice quality and VHI scores among the teachers of the experimental group does not correlate with age, teaching experience, or vocal demand. These results confirm those reported in previous literature [9].

With regard to the point of view of the children, most of the teachers in the study reported that children became immediately used to the novelty, and they also benefitted from listening. Also this aspect is in agreement with some previous reports indicating that poor voice quality in teachers reduces the intelligibility of speech [14,15,24,25], while amplification both reduces the need for repetition and permits better concentration [15].

In conclusion, our study corroborates previous data supporting the effectiveness of amplification in reducing the vocal load in schoolteachers. Moreover, the amplifier was received with great success. Therefore, especially in selected teachers with constitutional weak voice and/or in teachers prone to vocal chord pathology, vocal amplifiers may be an effective and low-cost intervention to decrease the potentially damaging vocal loads and may represent a necessary form of prevention.

\section{REFERENCES}

1. De Jong F, Kooijman P, Thomas G, Huinck W, Graamans K, Schutte H. Epidemiology of voice problems in Dutch teachers. Folia Phoniatr Logop 2006;58(3):186-98.

2. Kooijman PG, de Jong F, Thomas G, Huinck W, Donders R, Graamans K, et al. Risk factors for voice problems in teachers. Folia Phoniatr Logop 2006;58:159-74. 
3. Preciado-López J, Pérez-Fernández C, Calzada-Uriondo M, Preciado-Ruiz P. Epidemiological study of voice disorders among teaching professionals of La Rioja, Spain. J Voice 2008;22:489-508.

4. Van Houtte E, Claeys S, Wuyts F, Van Lierde K. The impact of voice disorders among teachers: vocal complaints, treatmentseeking behavior, knowledge of vocal care, and voice-related absenteeism. J Voice 2011;25(5):570-5.

5. Morton V, Watson D. The teaching voice: problems and perceptions. Logop Phoniatr Vocol 1998;23:133-9.

6. Rogerson J, Dodd B. Is there an effect of dysphonic teachers' voices on children's processing of spoken language? J Voice 2005;19(1):47-60.

7. Sato H, Bradley JS. Evaluation of acoustical conditions for speech communication in working elementary school classrooms. J Acoust Soc Am 2008;123:2064-77.

8. ANSI S12.60-2002. Acoustical performance criteria, design requirements, and guidelines for schools. Melville, NY: Acoustical Society of America; 2002.

9. Bovo R, Galceran M, Petruccelli J, Hatzopoulos S. Vocal problems among teachers: evaluation of a preventive voice program. J Voice 2007;21:705-22.

10. Ruotsalainen JH, Sellman J, Lehto L, Isotalo LK, Verbeek JH. Interventions for preventing voice disorders in adults (Review). Cochr Database Syst Rev 2010;7:1-42.

11. Niebudek-Bogusz E, Kotyło P, Śliwińska-Kowalska M. Evaluation of voice acoustic parameters related to the vocalloading test in professionally active teachers with dysphonia. Int J Occup Med Environ Health 2007;20(1):25-30. DOI: 10.2478/v10001-007-0001-9.

12. Sapienza C, Crandell C, Curtis B. Effects of sound-field frequency modulation amplification on reducing teachers' sound pressure level in the classroom. J Voice 1999;13:375-81.

13. McCormick CA, Roy N. The ChatterVox ${ }^{\mathrm{TM}}$ portable voice amplifier: A means to vibration dose reduction? J Voice 2002;16:502-8.

14. Jónsdottir V, Rantala L, Laukkanen AM, Vilkman E. Effects of sound amplification on teachers' speech while teaching. Logop Phoniatr Vocol 2001;26(3):118-23.
15. Jónsdottir V, Laukkanen AM, Siikki I. Changes in teachers' voice quality during a working day with and without electric sound amplification. Folia Phoniatr Logop 2003;55:267-80.

16. Gaskill CS, O'Brien SG, Tinter SR. The effect of voice amplification on occupational vocal dose in elementary school teachers. J Voice 2012;26(5):19-27.

17. Morrow SL, Connor NP. Voice amplification as a means of reducing vocal load for elementary music teachers. J Voice 2011;25(4):441-6.

18. Roy N, Weinrich B, Gray S, Tanner K, Stemple J, Sapienza C. Three treatments for teachers with voice disorders: A randomized clinical trial. J Speech Lang Hear Res 2003;46: 670-88.

19. Roy N, Weinrich B, Gray S, Tanner K, Toledo S, Dove H, et al. Voice amplification versus vocal hygiene instruction for teachers with voice disorders: A treatment outcomes study. J Speech Lang Hear Res 2002;45:625-38.

20. Jacobson BH, Johnson A, Grywalski C, Silbergleit A, Jacobson G, Benninger MS, et al. The Voice Handicap Index (VHI): Development and validation. Am J Speech Lang Path 1997;6:66-70.

21. MacKenzie K, Millar A, Wilson JA, Sellars C, Deary IJ. Is voice therapy an effective treatment for dysphonia? A randomised controlled trial. BMJ 2001;323:658-61.

22. Simberg S, Sala E, Tuomainen J, Sellman J, Ronnemaa AM. The effectiveness of group therapy for students with mild voice disorders: A controlled clinical trial. J Voice 2006;20:97-109.

23. Duffy OM, Hazlett DE. The impact of preventive voice care programs for training teachers: Longitudinal study. J Voice 2004;18:63-70.

24. Morton V, Watson DR. The impact of impaired vocal quality on children's ability to process spoken language. Logop Phoniatr Vocol 2001;26(1):17-25.

25. Jónsdóttir V. Cordless amplifying system in classrooms. A descriptive study of teachers' and students' opinions. Logop Phoniatr Vocol 2002;27:29-36.

This work is available in Open Access model and licensed under a Creative Commons Attribution-NonCommercial 3.0 Poland License - http://creativecommons.org/ licenses/by-nc/3.0/pl/deed.en. 